\title{
The effect of energy performance regulations on energy consumption
}

\author{
Olivia Guerra-Santin • Laure Itard
}

Received: 3 December 2010 / Accepted: 18 January 2012 / Published online: 8 February 2012

(C) The Author(s) 2012. This article is published with open access at Springerlink.com

\begin{abstract}
Governments have developed energy performance regulations in order to lower energy consumption in the housing stock. Most of these regulations are based on the thermal quality of the buildings. In the Netherlands, the energy efficiency for new buildings is expressed as the EPC (energy performance coefficient). Studies have indicated that energy regulations are successful in lowering the energy consumption in residential buildings. However, the actual energy consumption is usually different from the expected energy consumption. This paper explores the effectiveness of energy performance regulations in lowering the energy consumption of dwellings built in the Netherlands after 1996. The effect of the EPC and thermal characteristics on energy consumption was determined by statistical analyses of data on actual energy consumption. The results showed that energy reductions are seen in dwellings built after the introduction of energy performance regulations. However, results suggest that to effectively reduce energy consumption, the tightening of the EPC in not enough. Policies aimed at controlling the construction quality and changing occupant behaviour are also necessary to achieve further energy reductions.
\end{abstract}

O. Guerra-Santin $(\bowtie)$

Welsh School of Architecture, Cardiff University,

Cardiff, Wales, UK

e-mail: GuerraSantinO@cardiff.ac.uk

L. Itard

OTB Research Institute for the Built Environment, TU Delft,

Delft, Netherlands
Keywords Actual energy consumption · Energy performace regulations $\cdot$ Housing

\section{Introduction}

Worldwide, the built environment consumes $41 \%$ of the energy produced in developed countries. Of all the phases in the life-cycle of buildings the user phase is the most energy-intensive (Itard and Meijer 2008). In recent decades, governments all over the world have included energy requirements in their building regulations in a bid to lower energy consumption in the housing stock. Most of these regulations are based on the thermal quality of the buildings and thus aim to reduce the energy spent on heating space.

Since 2003, the Energy Performance Building Directive has required all EU member states to implement performance-based energy regulations (European Commission, $2003 \mathrm{MB}$ ) to lower the energy required for heating, cooling, ventilation, lighting and domestic hot water in buildings. In the Netherlands, energy consumption in new buildings has been regulated since 1975 . Prior to 1995 , energy efficiency regulations consisted only of limits on transmission losses based on insulation values. In 1995, they were expanded to include the EPC (energy performance coefficient), a non-dimensional figure that expresses the energy efficiency of a building on the basis of the energy consumed for heating, hot water, lighting, ventilation, humidification and cooling. The EPC is determined by dividing the calculated energy 
requirement of a building by a standardised energy performance, which is based on the heat-transfer surface and the total heated area of the dwelling.

The EPC applies a correction for building size to avoid penalising larger dwellings or dwellings with larger heat loss surfaces (e.g. corner houses or detached houses). It sets a limit on energy consumption, allowing designers to make trade-offs and devise a solution from many options (e.g. using more insulation or more energy-efficient systems). In 1996 the EPC stood at 1.4, a value that was easy to reach with common construction methods at the time. It was tightened to 1.2 in 1998 , to 1.0 in 2000 and to 0.8 in 2006. In addition to the EPC, the energy regulations in the Netherlands apply an $R_{\mathrm{c}} \geq 2.5 \mathrm{~m}^{2} \mathrm{~K} / \mathrm{W}$ for external walls, roofs and ground floors and a $U \leq 4.2 \mathrm{~W} / \mathrm{m}^{2} \mathrm{~K}$ for windows, doors and window frames.

Various studies have indicated that energy regulations have been successful in lowering energy consumption in residential buildings. Leth-Petersen and Togeby (2001) found that building regulations have played a key role in lowering energy consumption in new dwellings. They recorded annual energy reductions of $3.5 \%$ to $4.8 \%$ depending on the type of heating system, though they do stress that some of this result might be due to the independent effect of better insulation, glazing and more efficient boilers. In a Dutch study on the effect of EPC values in ten low-energy projects (146 dwellings), Jeeninga et al. (2001) found that the energy requirement is determined primarily by the building envelope ( $R_{\mathrm{c}}, U$ value of glazing) and the type of dwelling besides the indoor temperature. They found only indicative differences (not statistically significant at $p<0.05$ level) for energy consumption in dwellings with different EPC levels except for categories 0.75 and 1.2. In yet another Dutch study, Beerepoot and Beerepoot (2007) concluded that energy performance regulations have led to the utilisation of more energy-efficient systems.

However, other studies have shown that the actual energy consumption is usually different from the predicted energy consumption. For example, Branco et al. (2004) found that actual energy consumption was 50\% higher than expected in energy-efficient multifamily dwellings in Denmark. They concluded that the difference was due to the exclusion of the actual utilisation conditions and the actual system performance. After discerning a rebound effect of $15-30 \%$, Haas et al. (1998) argued that energy savings from conservation measures would be lower than calculated. During a dwelling audit in the USA, Hirst and Goeltz (1985) also found that energy savings were lower than predicted. Some studies have established no relationship between energy consumption and the thermal quality of buildings (Haas et al. 1998; Sardianou 2008).

In a previous study (Guerra-Santin et al. 2009), which used statistical analysis to determine the effect of building characteristics, household characteristics and occupant behaviour, indicated that $42 \%$ of the variation in energy consumption could be explained by building characteristics. Caldera et al. (2008) and Tiberiu et al. (2008) identified a relationship between energy consumption and certain building characteristics, including the shape of the dwelling and $U$ values.

The EPC aims to reduce the overall building-related energy consumption in dwellings. In NEN 5128:2001, the EPC is defined as an instrument to assess energy reduction. In this chapter, we explore the role of energy performance regulations in lowering the energy consumption for space heating in dwellings built after 1996, the year in which new energy requirements were introduced in the Netherlands. The aims are (1) to determine the extent of the influence of the EPC level on reductions in energy consumption for heating; (2) to determine whether tighter regulations could help to further reduce energy consumption for space heating; and (3) to identify scope for improvement in the regulations in order to bring about a further reduction in energy consumption for heating. We achieved the third aim by studying the building characteristics (included in the EPC) that have a larger influence on energy consumption for space heating.

Although the EPC do not aim at predicting energy consumption, it is necessary to assess the effectiveness of the energy performance regulations since their tightening often imply higher investments from builders.

The effect of the EPC value and thermal characteristics on energy consumption was determined by statistical analyses of data on actual energy consumption in Dutch dwellings. A household survey was carried out on housing built after 1996. The data from the respondents were paired with data from EPC calculation files kept by the municipalities. Both the data and the methods are discussed in Data and methodology section. Results section deals with the relationship between the actual energy consumption and the energy performance regulations. Comparison of the results with a nationwide 
survey section compares the results with a larger sample using a database from a national household survey. The discussion is presented in Discussion section and the conclusions in Conclusions section.

\section{Data and methodology}

During the past 15 years, only four surveys have been conducted to assess the effectiveness of the energy performance regulations on the actual energy consumed for heating in the Netherlands. The first was carried out by Jeeninga et al. (2001) on a sample of 146 dwellings; the second by PRC and Uitzinger (2004) on a sample of 649 dwellings; the third in 2008 by the authors of this paper on a sample of 313 dwellings, in which we focus on this paper; and the last one by ECN/RIGO in 2010 assessing the effect on energy consumption of the EPC tightening from 1.0 to 0.8 on a sample of 248 dwellings.

The data were drawn from two sources: a survey among households in two districts in the Netherlands and EPC files from municipalities and architects' firms. The EPC files belonged to the dwellings where the survey was conducted, thus enabling us to match the response from the survey with the data on building characteristics.

The survey was carried out simultaneously in two districts in the Netherlands in autumn 2008. To ensure that the dwellings in the sample fell within the timescale of the EPC we specifically chose districts that were built after the EPC had been introduced. The districts were also chosen because they were representative of the Dutch situation in terms of dwelling type, heating system and ventilation. The sampling ensured the inclusion of dwellings built by a number of different architect offices and thus contractors, in order to control for the influence of the construction quality on the results of the study. The sample size was 313 households. Section 4 presents the analysis of a nationwide survey with a much larger random sample to determine the effect of the relatively small sample size and the sampling in only two districts of the OTB survey. The districts are described in detail below.

\section{Districts}

The chosen districts were Wateringse Veld in The Hague and Leidsche Rijn in Utrecht. Construction started in Wateringse Veld in 1996 and was still underway when the survey was being conducted (www. wateringseveld.nl). Leidsche Rijn is a district in Utrecht. Construction began in 1997 and will continue till 2025 (www.utrecht.nl).

All the dwellings in Wateringse Veld had individual central heating as opposed to Leidsche Rijn, where all but four had district heating. Balanced ventilation was better represented in Wateringse Veld, which also had a wider range of EPC values. Most dwellings in Leidsche Rijn had an EPC of 1.0 or 1.2, whereas all EPC values were represented in Wateringse Veld. There were far fewer maisonettes and detached houses in the sample than terraced houses, corner houses and flats. However, terraced and corner houses and flats are more common in the Netherlands.

\section{Energy consumption}

The respondents were asked to report their energy consumption from the last available annual energy bill. The energy data were corrected using heating degree days (HDD), based on the period from October 2006 to September 2007 (2,264.3 heating degree days for Utrecht and 2,186.9 for The Hague), since the years of the reported energy consumption ranged from 2005 to 2008. The HDD were taken from the Dutch Meteorological Institute (KNMI — Koninklijk Nederlands Meteorologish Instituut) obtained from www.kwa.nl. The HDD were weighted degree days. They used a baseline temperature of $18^{\circ} \mathrm{C}$.

Two types of energy for heating were used in the districts: heat (dwellings with district heating) and gas (dwellings with individual central heating). The energy reported from gas-heated dwellings included energy for space heating, water heating and cooking. The energy data from dwellings with district heating includes energy consumption for space and water heating, but not for cooking. These households cooked with electricity. Only gas was reported as primary energy. District heating is considered to have an efficiency of 0.95 in the Netherlands (NEN 5128: 2004). Energy for cooking and differences in system efficiency might therefore have had a slight effect on the reported energy consumption. However, gas for cooking was not expected to exceed 5\% (EuroACE 2004). This study focused on energy consumption for heating and included the energy consumption for heating tap water, which also figures in the EPC calculation. 


\section{EPC calculation}

The EPC data were obtained from municipalities, where they are kept according to requirements in the Dutch Building Decree, and were paired with the survey data. The EPC was not available in all cases. This was due to several reasons: building permission had been obtained just before the introduction of the EPC, the EPC files were missing, or the respondents did not state their address. This reduced the size of the sample (Table 1).

The EPC calculation takes account of the characteristics of the dwelling, the efficiency of the installations and standardised occupant behaviour based on an average Dutch household. The EPC document contains data on surfaces, $U$ values, infiltration level, type of heating system and type of ventilation system. The EPC calculation is one of the documents required to obtain a building permit. The building characteristics that are defined in the documents and used to calculate the EPC value should be the actual characteristics of the dwelling. The EPC is calculated as indicated in Table 2.

The total expected energy consumption $\left(Q_{\text {pres;tot }}\right.$ in Megajoules) is the sum of the primary energy required for space and water heating, the auxiliary energy for the heating system, and the energy required for ventilators, lighting and humidification based on standard data. The calculations for the primary energy take account of the efficiency of the installation, the distribution losses of the system, and the efficiency of electricity generation. Compensation for the energy obtained with photovoltaic systems is also included.

The total heated area ( $A_{\mathrm{g} \text {;verw }}$ in square meters) is the sum of the useful area of heated zones. The total heattransfer surface of the building ( $A_{\text {verlies }}$ in square meters) is calculated by multiplying the heat-transfer surfaces by a correction factor determined by the type of boundary: heated space, ground floor or basement, exterior or water, and unheated spaces. $C_{\mathrm{EPC}}$ is the correction factor

Table 1 Response rates and available data per district

\begin{tabular}{lllrr}
\hline District & $\begin{array}{l}\text { Response } \\
\text { from survey }\end{array}$ & $\begin{array}{l}\text { Reported } \\
\text { energy data }\end{array}$ & $\begin{array}{l}\text { EPC } \\
\text { data }\end{array}$ & $\begin{array}{l}\text { Reported energy } \\
\text { and EPC data }\end{array}$ \\
\hline $\begin{array}{l}\text { Leidsche } \\
\text { Rijn }\end{array}$ & 125 & 94 & 104 & 86 \\
$\begin{array}{l}\text { Wateringse } \\
\text { Veld }\end{array}$ & 177 & 147 & 138 & 131 \\
$\begin{array}{l}\text { Unknown } \\
\text { Total }\end{array}$ & 11 & 7 & 0 & 0 \\
\hline
\end{tabular}

for updates in methodology and has a fixed value for each update. This factor prevents punishing large houses or houses with larger heat loss surfaces. The calculation of the EPC value is presented in more detail in Table 2.

The variables obtained from the EPC are shown in Table 3. These variables were checked for normality and outliers with the Kolmogorov-Smirnov test, and for kurtosis and skewness. Outliers were found on heattransfer surface, total heated area, open surface (windows and doors) and closed surface (external walls), but they seemed to be real values (associated with large houses). Variables were therefore converted for normality.

\section{Methods of analysis}

The relationship between the building characteristics and the actual energy consumption was determined with statistical analyses performed with SPSS. Lower energy consumption was expected in dwellings with lower EPC values. Differences in the energy consumption for different EPC values section reports a one-way ANOVA test that was used to discern whether statistically significant reductions in energy consumption occurred in dwellings with lower EPC values.

As explained in EPC calculation section, the EPC calculation takes account of the energy required for space and water heating, ventilators, humidification, cooling and lighting. As this research was concerned with space and water heating (gas and heat) we did not study the energy required for electricity. In addition, no cooling or humidification equipment was found in the sample. Thus, subsequent analyses focused on the expected energy consumption for space and water heating $\left(Q_{\text {pres;verw }}\right.$ ${ }_{+}$tap; for details see Table 2). Since the building characteristics described in the EPC document are supposed to be the actual building characteristics, the expected energy consumption should be closely related to the actual energy consumption. First, a paired-sample $t$ test was applied to determine whether the actual energy consumption differed from the expected energy consumption for space and water heating. To further analyse the relationship between the EPC and the actual energy consumption and to identify scope for improvement in the energy regulations, Pearson product-moment correlation coefficients, independent-sample $t$ tests and oneway ANOVA tests were used to investigate relationships between the actual energy consumption and the building characteristics that were used to calculate the expected energy consumption for space heating $\left(Q_{\text {prim;verw }}\right)$. 
Table 2 EPC calculation

The EPC is calculated with the following formula:

$\mathrm{EPC}=\frac{Q_{\text {pres,tot }}}{\left[330 \times A_{\text {g,verwz }}\right]+\left[65 \times A_{\text {verlies }}\right]} \times \frac{1}{C_{\mathrm{EPC}}}(1)$

where,

$\mathrm{Q}_{\text {pres;tot }}$ is the value of the primary energy consumption in MJ, determined by eq. 2

$A_{\text {g;verwz }}$ is the value of the useful surface of the heated zones of the building in $\mathrm{m}^{2}$

$\mathrm{A}_{\mathrm{verlies}}$ is the value of the heat-transfer surface of the building in $\mathrm{m}^{2}$

$\mathrm{C}_{\mathrm{EPC}}$ is the correction factor for changes in the methodology

The required energy (MJ) is calculated with the following formula:

$Q_{\text {pres;tot }}=Q_{\text {prim;verw }}+Q_{\text {prim;hulp;verw }}+Q_{\text {prim;tap }}+Q_{\text {prim;vent }}+Q_{\text {prim;vl }}(2)$

where,

$\mathrm{Q}_{\text {prim;verw }}$ is the primary energy consumption for space heating in the building

$\mathrm{Q}_{\text {prim;hulp;verw }}$ is the primary auxiliary energy consumption for space heating

$\mathrm{Q}_{\text {prim;tap }}$ is the primary energy consumption for water heating

$\mathrm{Q}_{\text {prim;vent }}$ is the primary energy consumption for ventilators

$\mathrm{Q}_{\text {prim;vl }}$ is the primary energy consumption for lighting

To determine the total heat-transfer surface of the building, the surfaces are multiplied by a reduction factor determined by the type of space limiting with the surface.

The primary energy consumption for space heating is calculated by dividing the energy needed for space heating by the efficiency of the installations. The energy needed for space heating is determined by subtracting the effective heat gain from the heat loss.

Heat loss takes account of the transmission and ventilation loss. It considers the difference between the average indoor $\left(18^{\circ} \mathrm{C}\right)$ and average outdoor $\left(5^{\circ} \mathrm{C}\right)$ temperature multiplied by the number of days in mega seconds $(212$ days). The considered indoor temperatures in Celsius degrees are:

$7-17 \mathrm{~h}=19$ (living area and 2 days in sleeping area), 16 (sleeping area 5 days)

17-23 $\mathrm{h}=21$ (living area and 2 days in sleeping area), 16 (sleeping area 5 days)

23-7 $\mathrm{h}^{\mathrm{a}}=16$ (living area and 2 days in sleeping area), 14 (sleeping area 5 days)

Heat gains take account of solar gains and internal heat gains. Solar gains are determined on the basis of orientation, reduction factors for shadows, solar entry factors and surface. Heat gains are calculated by multiplying the total heated area by 110 , which is calculated by multiplying the average heat gain $\left(6.0 \mathrm{~W} / \mathrm{m}^{2}\right)$ by the value of the length of the considered period ( 212 days) in mega seconds.

The primary energy consumption for heating water is determined by the gross energy requirement minus the yearly input of solar energy (in the case of a solar boiler) and divided by the efficiency of the tap water system. The gross energy requirement is calculated with the gross energy in the bathroom installations divided by the efficiency of the systems. The primary energy consumption for ventilators is determined by the energy consumption of the ventilator divided by the efficiency of the electricity. The calculation assumes that mechanical ventilators are constantly working. The primary energy consumption for lighting is determined by multiplying the heated area of the dwelling by a factor of 22 and dividing it by the efficiency of the electricity. The factor 22 is obtained by multiplying the electricity needed for lighting $1 \mathrm{~m}^{2}$ of the surface $\left(6.0 \mathrm{kWh} / \mathrm{m}^{2} /\right.$ year) by 3.6 (which is the conversion from $\mathrm{kWh}$ to $\mathrm{MJ}$ ).

Source: NEN 5128 (2001)

a Thermostat setting

\section{Results}

Differences in the energy consumption for different EPC values

To determine whether houses with lower EPC values have significantly lower energy consumption, a oneway ANOVA test was conducted to detect any statistically significant differences in the energy consumption in dwellings with different EPC values. Cases were categorised according to their EPC value: $0=$ no EPC, $1=[1.21-1.40], 2=[1.01-1.20], 3=[0.81-1.00]$, $4=[0.8]$. The EPC values were not necessarily related to the year when the EPC was tightened, since lower EPC values than those required by the regulations in the year of construction were also found in the sample. The number of cases in each category is listed in Table 3. The ANOVA results revealed a statistically significant difference between the EPC categories $(p<0.001)$. Post-hoc analyses were then 
Table 3 Descriptive statistics of variables from EPC calculation and the survey

\begin{tabular}{|c|c|c|c|c|}
\hline Variable & Description & $N$ & Mean & SD \\
\hline Number of bedrooms & Number of bedrooms in dwelling & 313 & 3.00 & 1.00 \\
\hline Heat-transfer surface $\left[\mathrm{m}^{2}\right]$ & $\begin{array}{l}\text { Sum of exterior surfaces of the dwelling in } \\
\text { square metres, } \\
\text { walls and floors in the ground floor are } \\
\text { multiplied by factor } 0.7\end{array}$ & 235 & 200.36 & 97.55 \\
\hline $\begin{array}{l}\text { Heat-transfer rate of closed } \\
\text { surfaces }\left[\mathrm{Wk}^{-1}\right]\end{array}$ & $\begin{array}{l}\text { Sum of surfaces of walls and roof multiplied } \\
\text { by the } U \text {-value of the surfaces }\end{array}$ & 224 & 54.43 & 22.84 \\
\hline Total heated area $\left[\mathrm{m}^{2}\right]$ & Area of the heated space in the dwelling & 235 & 127.33 & 35.02 \\
\hline $\begin{array}{l}\text { Actual energy use for space } \\
\text { and water heating }[\mathrm{MJ} / \text { year }]\end{array}$ & Energy for water and space heating in $\mathrm{MJ} / \mathrm{year}$ & 240 & 32598.32 & 22764.99 \\
\hline Variable & Category & & $N$ & $\%$ \\
\hline \multirow[t]{10}{*}{ EPC value } & & & 21 & 8.27 \\
\hline & 0.8 & & & \\
\hline & & & 50 & 19.69 \\
\hline & 1.0 & & & \\
\hline & & & 118 & 46.46 \\
\hline & 1.2 & & & \\
\hline & & & 46 & 18.11 \\
\hline & 1.4 & & & \\
\hline & None & & 19 & 7.48 \\
\hline & Total & & 254 & 100.00 \\
\hline \multirow[t]{3}{*}{ Type of ventilation system } & Mechanical exhaust ventilation (1) ${ }^{\mathrm{a}}$ & & 217 & 93.34 \\
\hline & Balanced ventilation $(2)^{\mathrm{b}}$ & & 18 & 7.66 \\
\hline & Total & & 235 & 100.00 \\
\hline \multirow[t]{4}{*}{ Type of temperature control } & Manual valves in radiators & & 81 & 26.04 \\
\hline & Manual thermostat & & 79 & 25.40 \\
\hline & Programmable thermostat & & 151 & 48.55 \\
\hline & Total & & 311 & 100.00 \\
\hline \multirow[t]{9}{*}{ Infiltration rate $(3)^{\mathrm{c}}$} & & & 38 & 16.81 \\
\hline & 0.65 & & & \\
\hline & & & 97 & 42.92 \\
\hline & 1.0 & & & \\
\hline & & & 27 & 10.63 \\
\hline & 1.2 & & & \\
\hline & & & 64 & 28.32 \\
\hline & 1.4 & & & \\
\hline & Total & & 226 & 100.00 \\
\hline
\end{tabular}

${ }^{a}$ Mechanical exhaust ventilation: these systems extract indoor air from a house while air from outside infiltrates trough leaks in the building shell and through passive vents like grilles or windows

${ }^{b}$ Balanced ventilation: these systems supply and exhaust approximately equal quantities of fresh outside air and polluted inside air, respectively. A balanced ventilation system has two fans and two duct systems, one for the supply and one for the exhaust. Heat recovery in a heat exchanger is applied between the warm exhaust air and the cold supply air

${ }^{\mathrm{c}}$ Air volume flow rate through construction (cracks) in cubic decimeters per second under a pressure difference of $10 \mathrm{~Pa}$

performed to identify the EPC categories with differences in energy consumption. A Tukey test revealed that statistical differences existed only between dwellings with and without an EPC category. There were no statistically significant differences in the energy consumption of dwellings with different EPC values (Fig. 1).
Real and predicted energy consumption

As mentioned in Real and predicted energy consumption section, the EPC takes account of different thermal characteristics of buildings when determining the energy required for space heating. Lower EPC values do not indicate lower energy consumption as energy 


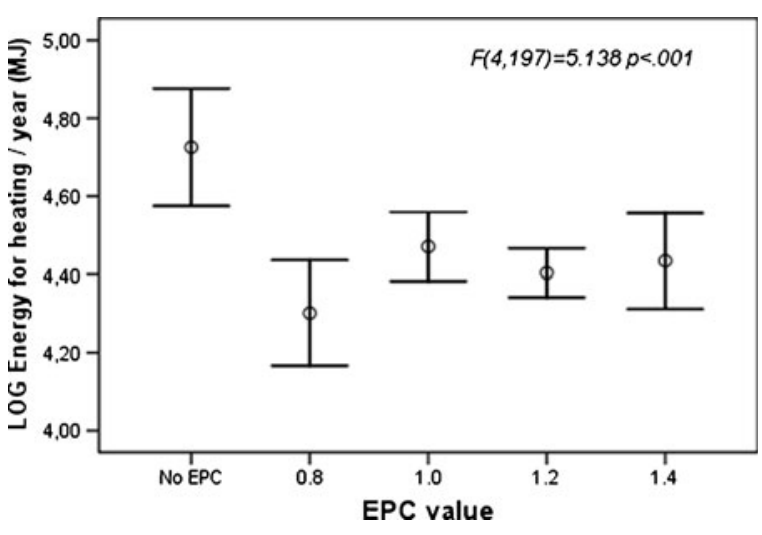

Fig. 1 Mean and 95\% confidence interval for actual energy consumption per EPC category (look for statistic)

consumption can vary widely within a value due to the neutralisation factor. The predicted energy consumption for space and water heating $\left(Q_{\text {pres;verw+tap }}\right)$ should be however, closely related to the actual energy consumption since this step has no correction for building size. A Pearson's correlation test was carried out to determine the relationship between the actual and predicted energy consumption. The calculated energy consumption refers here to the sum of the energy requirement for space and water heating in the EPC document $\left(Q_{\text {pres; verw+tap }}\right)$, corrected for the heating degree days in the period 2006-2007. A positive correlation was found between the actual and predicted energy consumption $(\rho=0.391, p<0.001, N=185)$. This indicates that the actual energy consumption is lower in dwellings with lower energy predictions $\left(Q_{\text {pres; tot }}\right)$.The correlation was, however, of medium size.

To check the accuracy of this prediction, a paired $t$ test was carried out between the expected energy consumption $\left(Q_{\text {pres;tot }}=Q_{\text {prim;verw }}+Q_{\text {prim;tap }}\right)$ and the actual energy required for heating. The test revealed a statistically significant difference between expected and actual energy consumption (Fig. 2). Contrary to assumptions, the actual energy consumption was lower than expected. Figure 3 illustrates this by showing the difference between the actual and expected energy consumption for a random selection of cases in the sample.

Lower EPC values did not seem to be related to lower energy consumption. However, energy consumption did show a medium-sized statistically significant correlation with the expected energy consumption for heating. As the EPC value was calculated with the expected energy consumption $\left(\mathrm{Q}_{\text {pres; verw+tap }}\right)$, other factors in the formula could have been affecting the relationship between the

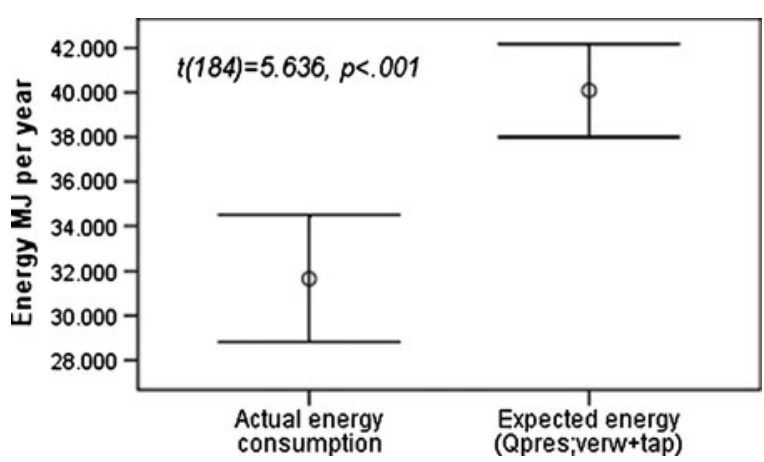

Fig. 2 Mean and 95\% confidence interval for actual energy consumption and expected energy consumption

EPC and the actual energy consumption. These differences might have been attributable to the neutralisation factor $\left(330 \times A_{\mathrm{g} \text {; verw }}+65 \times A_{\text {verlies }}\right)$ or the inclusion of the electricity required for ventilators and lighting and auxiliary energy for the heating system (see Fig. 4). Analyses were therefore carried out between (1) the total expected energy consumption and the actual energy consumption (Fig. 4a), and (2) between the EPC and the expected energy consumption (Fig. 4b).

A Spearman's rho correlation test showed that the total expected energy consumption $\left(Q_{\text {pres;tot }}\right)$ was positively correlated to the actual energy consumption ( $\rho=0.378$, $p<0.001, N=185$ ). The expected energy consumption for space and water heating ( $\left.Q_{\text {pres;verw+tap }}\right)$ was also correlated to the actual energy consumption $(\rho=0.391$, $p<0.001, N=185)$. The correlations are very similar and thus, we conclude that the inclusion of energy consumption for ventilators and auxiliary energy for the heating system in the EPC does not affect the relationship between the EPC value and the actual energy consumption.

ANOVA tests were conducted to determine whether the normalisation factor in the EPC calculation has an effect of the lack of correlation between EPC levels and energy consumption.

The first ANOVA test, showed that the total expected energy consumption $\left(Q_{\text {pres; tot }}\right)$ was statistically significantly different for different EPC values. The same results were found for the expected energy consumption for space and water heating $\left(Q_{\text {pres;verw+tap }}\right)$ (Fig. 5).The second ANOVA tests showed that the expected energy consumption for heating $\left(Q_{\text {pres;tot }}\right.$ and $\left.Q_{\text {pres;verw+tap }}\right)$ normalised per area was statistically significantly different for different EPC values (Fig. 6a and b). The comparison between the first and second ANOVA test indicates that 
Fig. 3 Actual and expected energy consumption per dwelling (selected cases)

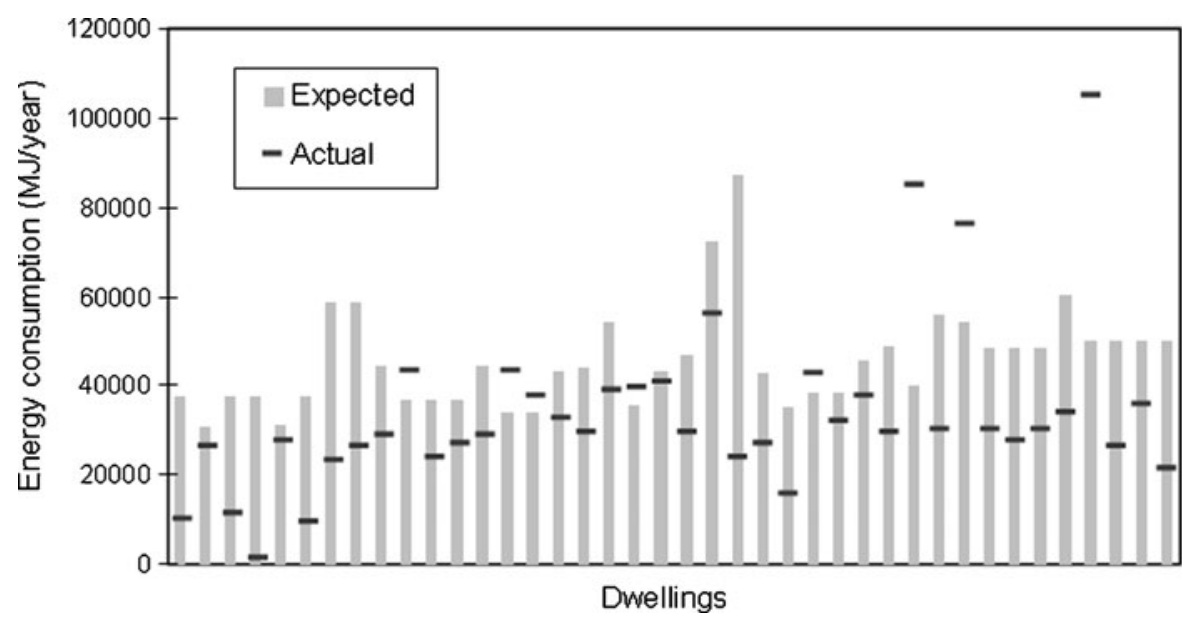

the relationship between the EPC and the expected energy consumption was much clearer when normalised per 'total heated area'. Hence, the normalisation factor might have had a small effect on the relationship between the actual energy consumption and the EPC

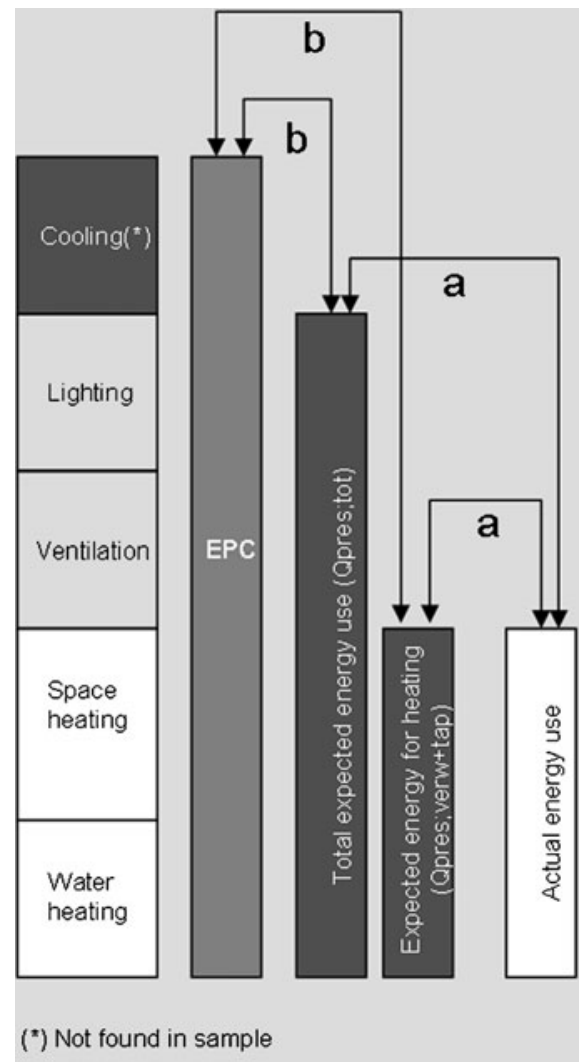

Fig. 4 Energy uses taken into account in the EPC and test carried out for the analysis value. From this we can conclude that the normalisation factor to correct for large areas and heat loss surfaces has an effect on the lack of correlation between EPC values and actual energy use.

Finally, Fig. 6c shows that no statistically significant difference was found in the actual energy consumption normalised per 'total heated area' for dwellings with different EPC levels. The normalisation factor in the EPC calculation has therefore a small influence in the lack of correlation between actual energy use and EPC levels.

Effect of thermal quality on energy consumption in dwellings

Under the energy performance regulations, the designer may choose from different options to achieve the expected energy performance. The fact that energy consumption for space and water heating is not statistically significant in dwellings with different EPC values might also be explained by trade-offs during the design/calculation phase (i.e. between energyefficient systems and thermal properties). Designers could be opting to reduce energy consumption in ways that are, in reality, less effective. A decision was therefore taken to investigate the relationship between building characteristics and the actual energy consumption. The analyses were conducted without normalisation per total heated area because the effect of dwelling size needed to be determined in relation to other factors. Moreover, as heated area correlated with all the other variables, multicollinearity problems were avoided.

Medium-sized positive statistically significant correlations were found between energy consumption on 
Fig. 5 Mean and 95\% confidence interval for the actual energy consumption (in Megajoules), total expected energy (in Megajoules) and expected energy for heating (in Megajoules) per EPC value

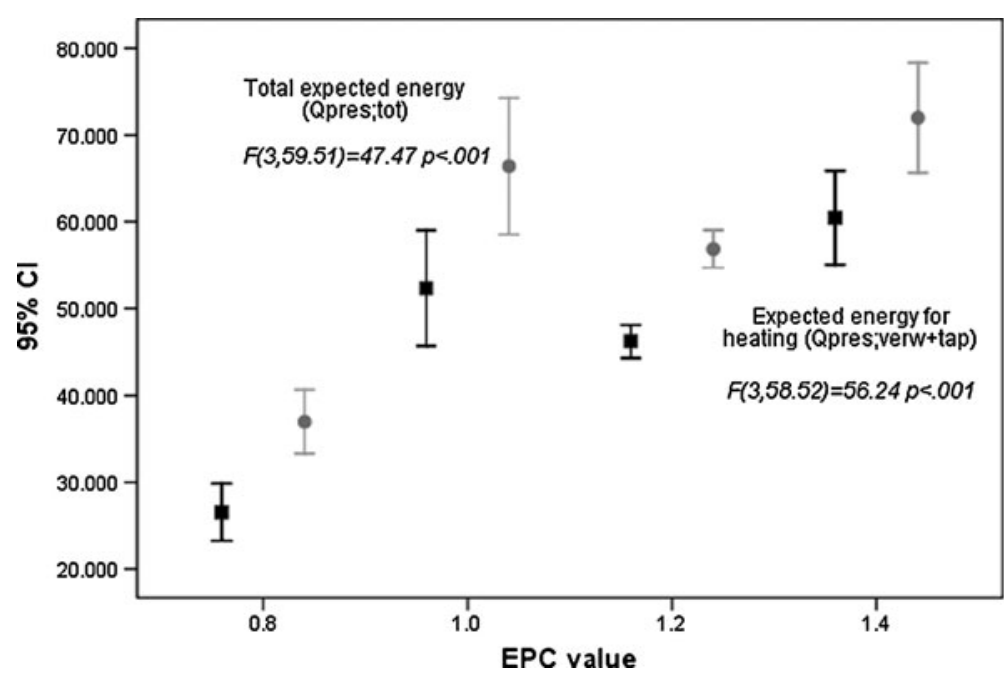

the one hand and 'number of bedrooms', 'heat-transfer surface' and 'heat-transfer rate of the closed surface' on the other. A small positive correlation was found between 'total heated area' and energy consumption (see Table 4 for statistics).

Analyses were performed to ascertain whether energy consumption was influenced by type of heating and ventilation system, and infiltration level. Independentsample $t$ test compared the energy consumption of dwellings with different types of ventilation and heating systems. Only a statistically significant difference was found between the energy consumption for mechanical ventilation and balanced ventilation, though the differences in the means were very small (Fig. 7). Balanced ventilation was found only in few cases, and all of them corresponded to dwellings with the lowest EPC levels
(1.0 and 0.8) suggesting a positive effect of the EPC on energy reductions.

A one-way ANOVA test did not point to any statistically significant differences in the case of dwellings with different levels of infiltration. (Fig. 8). It should be noted that these values came from the EPC calculations and not from the actual infiltration rates in the dwellings, since the energy performance regulations do not require to carry out air permeability tests.

\section{Comparison of the results with a nationwide survey}

The survey was performed in two selected districts, and a low response rate was obtained because of by the length of the questionnaire and detail of the questions.
Fig. 6 Mean and 95\% confidence interval for the actual energy consumption (in Megajoules per square meter), total expected energy (in Megajoules per square meter) and expected energy for heating (in Megajoules per square meter) per EPC value

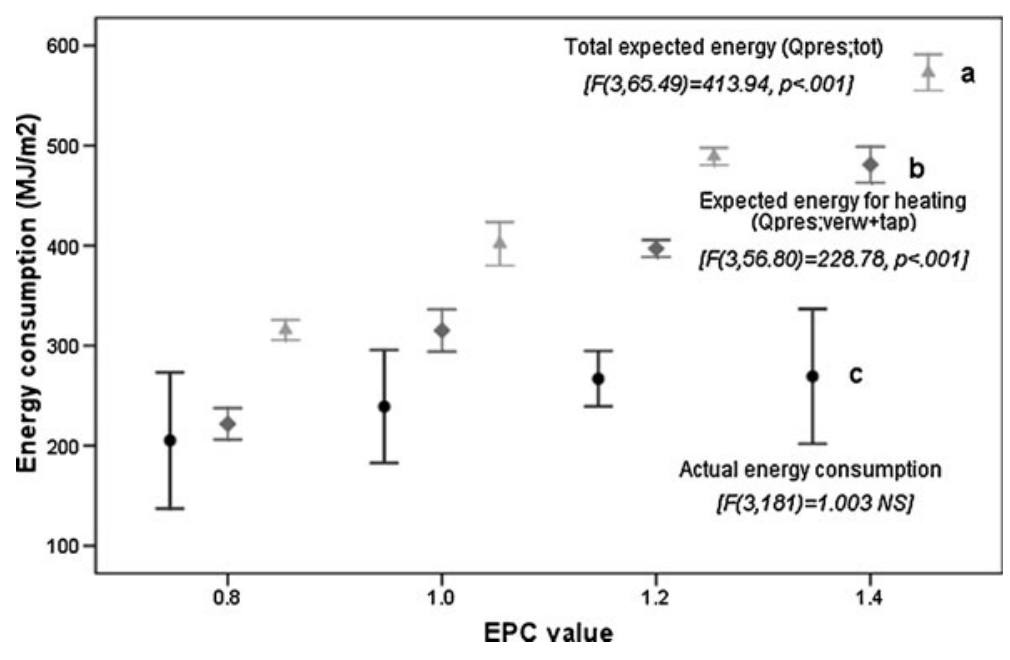


Table 4 Pearson product-moment correlation coefficients for building-related variables in the survey

\begin{tabular}{|c|c|c|c|}
\hline Variable & Variable & Statistic $(r)$ & $N$ \\
\hline \multirow[t]{4}{*}{ (LOG) Energy use (MJ/year) } & Number of bedrooms & $0.311^{*}$ & 240 \\
\hline & Heat-transfer surface $\left[\mathrm{m}^{2}\right]$ & $0.366^{*}$ & 191 \\
\hline & Heat-transfer rate of closed surface $\left[\mathrm{Wk}^{-1}\right]$ & $0.331 *$ & 180 \\
\hline & Total heating area $\left[\mathrm{m}^{2]}\right.$ & $0.262 *$ & 240 \\
\hline
\end{tabular}

$L O G$ means that the variable was transformed into a normal distribution with logarithm base 10 .

${ }^{*} p \leq 0.001$

This might have caused limitations in the results of this analysis. To validate the results of this study, the results were compared with the WoON database of the Dutch Ministry of Housing from 2005 (www.vrom.nl). The WoON database consists on a sample of 584 cases of dwellings built after 1996 and is a random sample across the Netherlands. The WoON database is similar to the OTB database, with the main exception of the EPC level which is not included in the WoON sample. We can validate the OTB survey with the WoON survey by repeating some statistical tests with comparable variables. The larger, random WoON sample would point at inconsistencies in the OTB sample.

The relationship between different building characteristics and energy consumption in the WoON database was investigated, which ascertained the generalisation of the results derived from our survey. The variables for the analysis are shown in Table 5.

The WoON database does not contain information on the $U$ values of the surfaces. However, the variables 'heat-transfer surface', 'total heated area' and 'number of bedrooms' showed correlations to energy consumption very similar to those found with our sample (Table 6).

Independent-sample $t$ tests were carried out to determine any differences in energy consumption

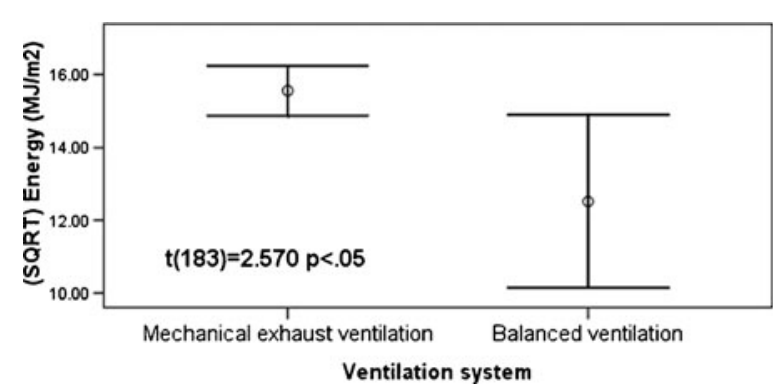

Fig. 7 Mean and 95\% confidence interval for energy consumption per ventilation type
(SQRT cubic meter gas) between dwellings with different ventilation systems. Only an indicatively lower energy consumption was found in houses with balanced ventilation $(t(585)=1.298$, not statistically significant). The effect of ventilation type on energy in our survey was statistically significant but with very small effect.

The results seem to indicate that the results of our survey are not too different to those obtained with a larger and random sample in the whole country; therefore the limitations caused by the characteristics of our sample can be disregarded.

\section{Discussion}

Relationship between the energy performance coefficient and actual energy consumption

No statistical differences in energy consumption were found for dwellings with different EPC values $(0.8,1.0$, 1.2 and 1.4), though we did find statistical differences

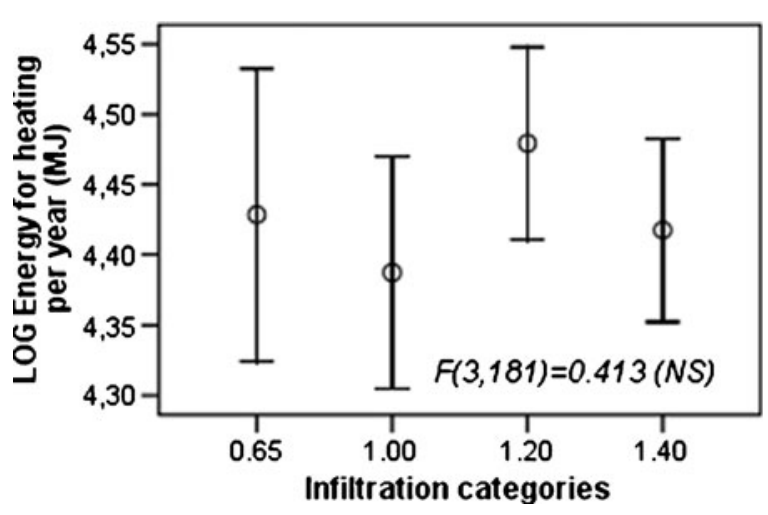

Fig. 8 Mean and 95\% confidence interval for energy consumption per infiltration level 
Table 5 Variables from WoON survey

\begin{tabular}{|c|c|c|c|c|}
\hline Variable & Description & $N$ & Mean & SD \\
\hline Number of bedrooms & Number of bedrooms in the dwelling & 586 & 4.02 & 1.33 \\
\hline Heat-transfer surface $\left[\mathrm{m}^{2}\right]$ & $\begin{array}{l}\text { Sum of exterior surfaces of the dwelling in square metres, walls } \\
\text { and floors on the ground floor are multiplied by a factor } 0.7\end{array}$ & 586 & 138.80 & 77.63 \\
\hline Total heated area $\left[\mathrm{m}^{2}\right]$ & Area of the heated space in the dwelling & 586 & 130.83 & 74.61 \\
\hline $\begin{array}{l}\text { Energy for water and space } \\
\text { heating }[\mathrm{MJ} / \text { year }]\end{array}$ & Actual energy used for water and space heating per year & 586 & 1068.89 & 676.32 \\
\hline Variable & Categories & & $N$ & $\%$ \\
\hline \multirow[t]{3}{*}{ Type of ventilation system } & Mechanical exhaust & & 476 & 82.2 \\
\hline & Balanced & & 103 & 17.8 \\
\hline & Total & & 586 & 100 \\
\hline
\end{tabular}

between dwellings built before and after the introduction of the EPC. This indicates that a reduction on energy consumption is seen in dwellings built after the introduction of the regulations, but the results of the tests suggest that tighter EPC levels do not necessarily reduce the energy consumption for space heating.

Further sections in this article aimed at finding the reason for the lack of correlation between the EPC and energy consumption (seen in Figs. 1 and 6c). Since the aim of the EPC is to realise an overall reduction in energy consumption, the calculations also take account of the energy required for lighting, cooling and hot water. This factor does not affect the relationship between the EPC and the actual energy consumption for space heating (as seen in Fig. 5) because standardised behaviour is used and the energy required for water, ventilation and lighting is therefore based solely in the 'total heated area' of the dwelling. Further results showed that the normalisation factor for dwelling size and heat loss surface has a small effect in the correlation between EPC level and actual energy consumption.

These results are in line with those of Jeeninga et al. (2001) in the Netherlands, who found only indicative

Table 6 Pearson product-moment correlation coefficients for building-related variables in the WoON survey

\begin{tabular}{llll}
\hline Variable & Variable & Statistic $(r)$ & $N$ \\
\hline (SQRT) Energy & Number of bedrooms & $0.341^{*}$ & 563 \\
use (MJ/year) & Heat-transfer surface $\left[\mathrm{m}^{2}\right]$ & $0.450^{*}$ & 563 \\
& Total heating area $\left[\mathrm{m}^{2]}\right.$ & $0.270^{*}$ & 563 \\
\hline
\end{tabular}

$S Q R T$ means that the variable was transformed into a normal distribution with square root

$* p \leq 0.001$ differences (not statistically significant at $p<0.05$ level) in energy consumption in dwellings with different EPC levels, except for categories 0.75 and 1.2. However, as the study was conducted in low-energy dwellings constructed before 2000 - when the EPC level was 1.0 - it is conceivable that 0.75 was experimental and was therefore more carefully implemented. In a larger sample, PRC Bouwcentrum (2004) found strong statistically significant differences between EPC categories. Although the statistical analysis could not be checked and there were concerns about the validity of the results (Itard et al. 2009), it still suggested that the effect of a tighter EPC is better observed in a larger sample. A later analysis of the sample (Uitzinger 2004) did not, however, find any correlation between equivalent gas consumption and EPC. The results of a more recent research carried out by ECN and RIGO (Menkveld and Leidelmeijer 2010) on a sample of 248 dwellings with EPC levels 0.8 and 1.0 are in accordance to the results of this study. They found that when energy consumption is corrected for occupant behaviour and building characteristics, there is a statistical significant difference between houses with EPC level 1.0 and 0.8. In the OTB sample, we found that energy consumption is correlated to the expected energy consumption, and with thermal properties; variables that are not influenced by occupant behaviour. In addition, in a previous study with the OTB database, correlations were also found between energy consumption and occupant behaviour (Guerra-Santin and Itard 2010).

Actual and expected energy consumption

A positive medium-sized correlation was found between the actual and expected energy consumption. This 
points to a relationship between building characteristics and actual energy consumption; however, this correlation was only medium size. A closer look at the sample revealed that the actual consumption was lower than the predicted consumption. This difference is believed to be caused by the differences between the occupant behaviour considered in the calculations and the actual behaviour of the occupants in the sample. The occupant behaviour used in the calculation (seen in Table 2) showed large differences in comparison to the actual occupant behaviour in the sample (Guerra-Santin and Itard 2010). People seem to spend far less time at home (therefore with the heating system off) than expected. In addition, large differences on occupant behaviour in similar houses have a large effect on energy consumption in energy-efficient dwellings.

Studies have indicated that the differences between actual and expected energy consumption could be also related to practices whereby buildings are not realised according to the official EPC specifications and to HVAC services that are run very differently than assumed on paper. A report by Nieman (2007) showed that $25 \%$ of dwellings in a sample of 154 fell short of the EPC requirements: the EPC was incorrectly calculated but the building permit was still issued. The realisation of $50 \%$ of the dwellings was not in accordance with the data used to calculate the EPC. In a 17-year study that monitored the energy performances of energy-efficient buildings, Gommans (2008) found that $40 \%$ of solar boilers functioned and only $25 \%$ of heat pumps reached the expected efficiency. This was essentially due to realisation faults, lack of control and lack of continuous monitoring. Another study by Elkhuizen et al. (2006) in office buildings showed that better monitoring could deliver energy savings of up to $28 \%$.

The only medium size correlation between the expected and the actual energy use might be therefore related to the actual building being different than the designed building. This idea is reinforced by the finding that the infiltration level was not found to be correlated to energy consumption.

Relationship between building characteristics and energy consumption

The determinants of actual energy consumption were further determined by statistical analyses of building characteristics. The results showed correlations between the actual energy consumption for water and space heating and the thermal properties of the building. In our sample statistically significant differences were found for different types of ventilation systems. The differences in energy consumption for different ventilation types were very small. These results indicate that thermal characteristics have a greater effect than the type of ventilation system efficiency on energy consumption; however, only a small number of dwellings with balanced ventilation were found in the sample.

The comparison with the WoON database delivered similar results with a slightly larger sample size and a random distribution across the Netherlands. Both databases showed similar correlations between thermal characteristics and energy consumption.

\section{Conclusions}

The aim of this study was to explore the role of energy performance regulations in lowering the energy consumption for space heating in energy-efficient dwellings. In addition, an analysis was carried out regarding the reductions in energy consumption after the regulations had been tightened.

Although the EPC does not aim specifically to reduce energy consumption for space heating, reductions in this area may be expected, since the thermal quality and the systems' efficiency of the dwellings are increased. That said, dwellings with lower EPC values do not appear to be correlated to less energy consumption for space and water heating, even when the type of dwelling or the size of the dwelling is taken into account.

The lack of correlation between EPC values and energy consumption for heating might be due to three factors: (1) the normalisation factor per dwelling size might have a small effect on the correlation between the EPC and energy consumption; however, this does not have an effect on the relationship between the expected and the actual energy consumption; (2) the differences between the building characteristics as described in the EPC calculations and the actual building characteristics (e.g. actual infiltration level); and (3) the effect of occupant behaviour on energy consumption. The first factor might have an effect on the relationship between the EPC value and the actual energy consumption, while the other two have an effect on the relationship between the expected and the actual energy consumption. 
A lower EPC value is expected to reduce energy consumption because it increases the energy efficiency of buildings. When the dwellings are built according to the regulations, those with lower EPC would have a lower consumption of energy if occupancy conditions are maintained equal in all dwellings. In this case, the energy performance regulations would be effectively reducing the energy consumption in newly built dwellings. However, the actual conditions of utilisation are not the same in all dwellings. This fact undermines the effectiveness of the energy performance regulations, since the range of behaviour hinders the effect of higher energy efficiency of dwellings. Nevertheless, the regulations have ensured that more energy-efficient dwellings were built after their introduction.

\section{Recommendations}

The fact that actual energy consumption for water and space heating showed a small correlation with the expected energy consumption and the fact that no differences in energy consumption were found in dwellings with different EPC values indicate that other factors besides building characteristics are having a strong effect on energy consumption. These factors are believed to be related to actual occupant behaviour and the actual properties of the dwellings. Further energy reductions could be achieved by focusing on changes in occupant behaviour in relation to the use of the heating and ventilation systems. In addition, thermal quality seems to be more effective than heatingsystem efficiency in reducing energy consumption for space heating.

The higher expected energy consumption in comparison to the actual energy consumption suggests large differences between the assumed and the actual occupant behaviour. More accurate information on the actual occupant behaviour and the identification of behaviour patterns to build energy-user profiles might improve the energy predictions in the energy performance regulations. Although accurate energy prediction is not the aim of the EPC, a better estimation of the actual energy performance and the actual energy savings expected from the introduction or tightening of building regulations, could be achieved.

Infiltration values, insulation levels and other building characteristics might be, in reality, different from those stated in the EPC calculation, thereby undermining the effect of the energy performance regulations. Further research should be aimed at determining whether the real quality of dwellings corresponds with the characteristics described in the EPC document and at finding better methods to guarantee the quality of the construction work.

In previous studies, correlations were found between building characteristics, occupant behaviour and household characteristics. To gain deeper insight into the real effect of building regulations on energy consumption, it is necessary to understand the influence of building characteristics on occupant behaviour, especially in terms of the rebound effect identified in other studies (Hens et.al., 2010; Haas et al. 1998). Such an effect might also be undermining the effectiveness of building regulations.

Given that a tighter EPC did not lower energy consumption for heating and that there are large differences between the expected and the actual energy consumption, it might be sensible to search for more efficient means to further lower the energy consumption of energy-efficient housing. This could be achieved by ensuring correct realisation and monitoring of the calculated performances, by paying attention to the knowledge needed by contractors, by implementing an effective building control process (Visscher et al. 2003) and by the implementation of policies directed to influence occupant behaviour.

Open Access This article is distributed under the terms of the Creative Commons Attribution License which permits any use, distribution, and reproduction in any medium, provided the original author(s) and the source are credited.

\section{References}

Beerepoot, M., \& Beerepoot, N. (2007). Government regulations as an impetus for innovations. Evidence for energy performance regulation in the Dutch residential building sector. Energy Policy, 35, 4812-4825.

Branco, G., Lachal, B., Gallinelli, P., \& Weber, W. (2004). Expected versus observed heat consumption of a low energy multifamily complex in switzerland based on long-term experimental data. Energy and Building, 36, 543-555.

Caldera, M., Corgnati, S. P., \& Filippi, M. (2008). Energy demand for space heating through a statistical approach: application to residential buildings. Energy \& Buildings, 40, 1972-1983. 
Elkhuizen, P., J.E. Scholten \& E. Rooiakkers (2006). Quality Control of HVAC services: evaluation of existing instruments and a vision for the future [in Dutch], TNO Bouw/Halmos report for Senter Novem.

EuroACE (2004). Towards Energy Efficient Buildings in Europe, final report June (ec.europa. eu).

Gommans, L.J. (2008). Energie prestaties van energie-efficiënt gebouwen: tussen ontwerp en werkelijkheid, TVVL magazine, September 2008, pp. 18-24

Guerra-Santin, O., \& Itard, L. (2010). Occupants' behaviour: determinants and effects on residential heating consumption. Building Research \& Information, 38(3), 318-338.

Guerra-Santin, O., Itard, L., \& Visscher, H. (2009). The effect of occupancy and building characteristics on energy use for space and water heating in Dutch residential stock. Energy \& Buildings, 41, 1223-1232.

Haas, R., Auer, H., \& Biermayr, P. (1998). The impact of consumer behaviour on residential energy demand for space heating. Energy and Buildings, 27, 195205.

Hens, H., Parijs, W., \& Deurinck, M. (2010). Energy consumption for heating and rebound effects. Energy and Buildings, 42, 105-110.

Hirst, E., \& Goeltz, R. (1985). Comparison of actual energy saving with audit predictions for homes in the north central region of the USA. Building and Environment, 20(1), $1-6$.

Itard, L., \& Meijer, F. (2008). Towards a Sustainable Northern European Housing Stock: Figures, facts and future. Amsterdam: IOS.

Itard, L., A. Meijer \& O. Guerra Santin (2009). Consumentenonderzoek Lenteakkoord, OTB/TU Delft report, Delft.
Jeeninga, H., M. Uyterlinde \& J. Uitzinger (2001). Energieverbruik van energiezuinige woningen, Report ECN \& IVAM, ECN-C01-072.

Leth-Petersen, S., \& Togeby, M. (2001). Demand for space heating in apartment blocks: measuring effect of policy measures aiming at reducing energy consumption. Energy Economics, 23, 387-403.

Menkveld, M. \& K. Leidelmeijer (2010). Evaluatie EPCaanscherping woningen, ECN \& RIGO, ECN-E-10-043

NEN 5128 (2004). Energy Performance of Residential functions and residential buildings: determination method, ics 91.120.10, March.

NEN 5128 norm (2001).

Nieman (2007). Eindrapportage woonkwaliteit binnenmilieu in nieuwbouwwoning, Report Wu060315aaA4.PK, VROM Inspectie Regio Oost, Arnhem.

PRC Bouwcentrum BV (2004). EPC en energieverbruik nieuwbouwwoningen, Report Novem, Kompas Utrecht.

Sardianou, E. (2008). Estimating space heating determinants: an analysis of Greek households. Energy and Buildings, 40, 1084-1093.

Tiberiu, C., Virgone, J., \& Blanco, E. (2008). Development and validation of regression models to predict monthly heating demand for residential buildings. Energy \& Buildings, 40, 1825-1832.

Uitzinger, J. (2004). Analyse EPC en energieverbruik bij woningen, Report IVAM/SenterNovem

Visscher, H.J., F.M. Meijer \& L. Sheridan (2003). Effective and efficient building control, proceedings CIB-CTBUH International Conference on Tall Buildings, Strategies for performance in the aftermath of the World Trade Centre, Malaysia, 8-10 May, pp. 721-726. 